\title{
Overexpression of NEDD9 in renal cell carcinoma is associated with tumor migration and invasion
}

\author{
JUE WANG ${ }^{1,2}$, SI WANG $^{3}$, YUN LUAN $^{1,2}$, WENHUA ZHANG $^{4}$, CHAO SUN $^{1}$, GUANGHUI CHENG $^{1}$, \\ KAILIN LI ${ }^{1}$, QIAN XIN ${ }^{1}$, ZHAOMIN LIN ${ }^{1}$, TONGGANG QI ${ }^{1}$ and FENG KONG ${ }^{1,2}$ \\ ${ }^{1}$ Central Laboratory; ${ }^{2}$ Key Laboratory for Kidney Regeneration of Shandong Province, The Second Hospital of \\ Shandong University, Jinan, Shandong 250033; ${ }^{3}$ Department of Neurology, Jinan Central Hospital \\ Affiliated to Shandong University, Jinan, Shandong 250013; ${ }^{4}$ Department of Urology, \\ Qilu Hospital, Shandong University, Jinan, Shandong 250012, P.R. China
}

Received September 2, 2016; Accepted September 7, 2017

DOI: 10.3892/ol.2017.7231

\begin{abstract}
Scaffold protein neural precursor cell expressed, developmentally downregulated 9 (NEDD9) is a member of the Crk-associated substrate protein family and is known to be a biomarker in multiple cancer types. It serves a critical function in regulating cell proliferation, migration, invasion and survival. The objective of this study was to evaluate the potential effects of NEDD9 in renal cell carcinoma (RCC). The expression of NEDD9 was analyzed by immunohistochemistry, western blotting and reverse transcription-quantitative polymerase chain reaction. NEDD9 protein and mRNA levels were significantly upregulated in RCC tissues compared with normal tissues $(\mathrm{P}<0.001)$. Furthermore, the NEDD9 immunostaining level was significantly associated with primary tumor stage and tumor, node, metastasis stage $(\mathrm{P}<0.05)$. High NEDD9 expression resulted in significantly lower survival rates for patients compared with normal NEDD9 expression $(\mathrm{P}<0.01)$. In addition, wound healing and transwell assays indicated that NEDD9 depletion by small interfering RNA significantly attenuated the migration and invasion of RCC cells $(\mathrm{P}<0.001)$. The present data suggested that NEDD9 may be a novel target for prevention and treatment of RCC metastasis and recurrence.
\end{abstract}

\section{Introduction}

Kidney tumor is one of the most common causes of cancer-related cases of mortality, with $>270,000$ people expected to be diagnosed with kidney cancer every year (1).

Correspondence to: Dr Feng Kong, Central Laboratory, The Second Hospital of Shandong University, 247 Beiyuan Road, Jinan, Shandong 250033, P.R. China

E-mail: kongfeng@sdu.edu.cn

Key words: neural precursor cell expressed developmentally downregulated 9, renal cell carcinoma, clinicopathological factors, migration, invasion
According to global cancer statistics in 2013, RCC is the most prevalent subtype of kidney cancer, accounting for approximately $80-90 \%$ of cases, and a continued increase in the incidence of RCC has been reported $(1,2)$. Although surgical excision remains the curative treatment when RCC has not metastasized, a large proportion of patients will relapse or develop metastatic disease (3). However, treatment options for renal cancer are limited since it responds poorly to chemotherapy and radiotherapy (4). Therefore, understanding the molecular mechanisms of RCC cell invasion and metastasis is imperative for early diagnosis and treatment of RCC.

NEDD9 was first identified in neuronal precursor cells as a downregulated gene during the development of the mouse central nervous system. It belongs to the Crk-associated substrate family, which is essential for pro-metastasis behavior in several types of solid tumor (5). Growing evidence has identified NEDD9 as a tumor-promoting factor in melanomas (6), glioblastomas $(7)$, breast carcinoma $(8,9)$, colorectal cancer and lung cancers (10). It serves a critical function in regulating cell proliferation, migration, invasion and survival $(11,12)$. Silencing of NEDD9 in vivo significantly reduced tumor progression in NEDD9(-/-) mice (13). Furthermore, a recent study indicated that miR-145 may exhibit tumor suppressive functions through regulating NEDD9 oncogenic genes in RCC (12). However, the expression and biological function of NEDD9 in RCC remains largely unknown.

In a previous study by the current group, it was reported that NEDD9 is overexpressed in RCC (11). In the present study, NEDD9 expression was evaluated in a large cohort of patients with RCC, and its clinical and biological significance was analyzed in a retrospective manner.

\section{Materials and methods}

Clinical RCC specimens and RCC cell lines. The present study recruited a total of 68 pathologically confirmed patients with RCC who underwent complete resection of the metastatic lesions and 6 normal renal tissues were from the tumor bearing kidneys, between January 2013 and December 2015 at the Department of Urology, the Second Hospital and Qilu Hospital of Shandong University (Jinan, China). Follow-up information 
was obtained from a review of the patients' medical records. All patients had no preoperative radiotherapy, chemotherapy or immunotherapy. A total of 20 pairs of fresh clear cell RCC (ccRCC) tissues and matched normal renal tissues were also stored at $-80^{\circ} \mathrm{C}$ immediately after resection for protein extraction and reverse transcription-quantitative polymerase chain reaction (RT-qPCR) analysis. Detailed clinicopathological information of the patients is listed in Table I. For all samples, pathologic tumor stage, $\mathrm{N}$ stage, TNM stage, histological grade and renal vein invasion were reevaluated and determined according to the tumor node metastasis staging system (14). The study was reviewed and approved by the Ethical Committee of the Second Hospital of Shandong University. Written informed consent was provided by all patients for the use of their samples and data in the study.

Human RCC cell lines 786-O and Caki1 were purchased from the American Type Culture Collection (Manassas, VA, USA). The cells were cultured at $37^{\circ} \mathrm{C}$ in RPMI 1640 medium containing $10 \%$ fetal bovine serum (FBS; Invitrogen; Thermo Fisher Scientific, Inc., Waltham, MA, USA), 100 U/ml penicillin (Sigma-Aldrich; Merck KGaA, Darmstadt, Germany), and $100 \mu \mathrm{g} / \mathrm{ml}$ streptomycin (Sigma-Aldrich; Merck KGaA).

$R N A$ preparation and $R T-q P C R$. Total RNA was extracted from frozen ccRCC tissues using a commercial guanidinium isothiocyanate-based kit (Buffer RZ, Tiangen Biotech Co., Ltd., Beijing, China), following the manufacturer's protocol. The amount of RNA in the sample was quantified spectrophotometrically at a $260 \mathrm{~nm}$ wavelength. First strand cDNA was synthesized using $2 \mu \mathrm{g}$ total RNA and M-MLV retroviridase (Takara Bio, Inc., Otsu, Japan) at $37^{\circ} \mathrm{C}$ for $15 \mathrm{~min}$, then $85^{\circ} \mathrm{C}$ for $5 \mathrm{sec}$. Oligonucleotide primers were synthesized by Sangon BiotechCo.,Ltd.(Shanghai,China).Primer sequences used were as follows: NEDD9 forward, 5'-GGGTAAAAAGGTGATAAC CCCCGT-3' and reverse, 5'-TGCTGATGAGGGAGGGAT GTCGT-3'; $\beta$-actin forward, 5'-TCCATCATGAAGTGTGA CGT-3' and reverse, 5'-GAGCAATGATCTTGATCTTCAT-3'. qPCR was performed in the ABI PRISM 7500 Sequence Detection system (Applied Biosystems; Thermo Fisher Scientific, Inc.) using SYBR ${ }^{\circledR}$ Fast qPCR Mix (Takara Bio, Inc.). Relative expression level was determined using the $2^{-\Delta \Delta C \mathrm{C}}$ method (15). NEDD9 expression in cell lines were evaluated by semi-quantitative PCR, with $\beta$-actin used as the control. The reaction conditions were as follows: $95^{\circ} \mathrm{C}$ for $30 \mathrm{sec}, 64^{\circ} \mathrm{C}$ for $25 \mathrm{sec}$ and $72^{\circ} \mathrm{C}$ for $30 \mathrm{sec}$, for a total of 35 cycles. Agarose gel electrophoresis was performed after the reaction, and the products were observed using an ultraviolet imaging system. The experiments were performed in triplicate.

Immunohistochemistry. Immunohistochemistry assay were performed on tissues collected from 68 pathologically confirmed patients with RCC and 6 normal renal tissues. Immunohistochemistry experiments were performed as described previously (11). In brief, representative samples were placed into $4 \%$ paraformaldehyde overnight and then 5-mm paraffin sections were prepared for the experiments. Sections were deparaffinized in xylene, rehydrated which was hydrate by placing in 95, 70, 50 and 30\% ethanol for 2 min each, and endogenous peroxidase activity was quenched by $3 \%$ hydrogen peroxide in methanol. The sections were submerged in $10 \mathrm{mM}$ citrate buffer ( $\mathrm{pH}$ 6.0) and microwaved for 8-15 min for antigen retrieval. Non-specific binding was blocked by incubation with normal goat serum (Beijing Zhongshan Golden Bridge Biotechnology Co., Ltd., Beijing, China) for $1 \mathrm{~h}$ at room temperature, and the slides were incubated with NEDD9 rabbit monoclonal primary antibodies (cat. no. ab37161; 1:200; Abcam, Cambridge, MA, USA) at $4^{\circ} \mathrm{C}$ overnight. After washing, sections were incubated with horseradish peroxidase-conjugated goat anti-rabbit $\mathrm{IgG}$ at room temperature for $1 \mathrm{~h}$ (cat. no. SPN-9001; 1:50; Beijing Zhongshan Golden Bridge Biotechnology Co., Ltd.). Color was developed with the DAB Horseradish Peroxidase Color Development kit and imaged using bright field light microscopy.

IHC evaluation. Slides were evaluated by two independent pathologists without any prior information of the clinicopathological variables and survival data. NEDD9 expression was scored using a reproducible semiquantitative method considering staining intensity $(0$, no staining of the tumor cells; 1 , light yellow staining; 2 , moderate to deep yellow staining; and 3, brown staining) and the percentage of positive staining $(0,0-5 \% ; 1,6-25 \% ; 2,26-50 \% ; 3,51-75 \%$; and 4 , $>76 \%$ ). Conflicting scores were resolved by consensus. Cases with combined scores of 0-4 were defined as the low-expression group, and cases with scores of 5-7 were defined as the high-expression group.

NEDD9 small interfering (si)RNA transfection. NEDD9 small interfering (si)RNA transfection was performed on 786-O and Caki1 cells. Knockdown of NEDD9 expression was performed by RNA interference using specific siRNA oligonucleotides. The target sequence was: 5'-UCCCAUGCAGGAGACUGC CUCCAGU-3'. The chemically modified siRNAs targeting NEDD9 and scramble siRNA were purchased from Invitrogen (Thermo Fisher Scientific, Inc.). Cells were transfected with either NEDD9 or control siRNA with a concentration of 100 nM using Lipofectamine RNAiMAX reagent (Invitrogen; Thermo Fisher Scientific, Inc.), following the manufacturer's protocol. All experiments were performed $72 \mathrm{~h}$ after transfection.

Western blot analysis. Western blot analysis was performed as described previously (11). Total proteins extracted from frozen tissues and cells lines transfected for $72 \mathrm{~h}$ and then incubated with RIPA lysis buffer (DBI Bioscience, Shanghai, China), following the manufacturer's protocol. After protein quantitation using a BCA Protein Quantitative kit (DBI Bioscience), $100 \mu \mathrm{g}$ protein per lane were separated by SDS-PAGE $(10 \%$ gel) and blotted onto polyvinylidene difluoride membranes. The membranes were blocked with $5 \%$ skim milk and then incubated overnight at $4^{\circ} \mathrm{C}$ with anti-NEDD9 $(1: 1,000$; cat. no. ab37161; Abcam) or anti-tubulin (cat. no. sc-8035; 1:1,000; Santa Cruz Biotechnologies, Inc., Dallas, TX, USA), followed by incubation with horseradish peroxidase-conjugated IgG goat anti-rabbit H\&L; (cat. no. ab97051; 1:2,000; Abcam) and goat anti-mouse IgG H\&L (cat. no. ab6708; 1:2,000; Abcam) at room temperature for $1 \mathrm{~h}$. An enhanced chemiluminescence kit (Merck KGaA) was used for detection using FluorChem ${ }^{\text {TM }} \mathrm{Q}$ software (version 3.4.0.0; Protein Simple, San Jose, CA, USA). The experiments were performed in triplicate. 
Table I. Association between NEDD9 expression and clinicopathological factors in renal cell carcinoma.

\begin{tabular}{|c|c|c|c|}
\hline $\begin{array}{l}\text { Clinicopathological } \\
\text { factor }\end{array}$ & $\mathrm{n}$ & $\begin{array}{l}\text { Overexpressing } \\
\text { NEDD9, n }(\%)\end{array}$ & P-value \\
\hline Age (years) & & & 0.495 \\
\hline$>60$ & 35 & $24(68.57)$ & \\
\hline$<60$ & 33 & $20(60.61)$ & \\
\hline Sex & & & 0.701 \\
\hline Male & 52 & $33(63.46)$ & \\
\hline Female & 16 & $11(68.75)$ & \\
\hline T stage & & & 0.011 \\
\hline $\mathrm{T}_{1}$ & 23 & $11(47.82)$ & \\
\hline $\mathrm{T}_{2}$ & 15 & $8(53.33)$ & \\
\hline $\mathrm{T}_{3}$ & 21 & $18(85.71)$ & \\
\hline $\mathrm{T}_{4}$ & 9 & 7 (77.78) & \\
\hline $\mathrm{N}$ stage & & & 0.414 \\
\hline $\mathrm{N}_{0}$ & 56 & $35(62.50)$ & \\
\hline $\mathrm{N}_{1,2}$ & 12 & $9(75)$ & \\
\hline TNM stage & & & 0.045 \\
\hline I, II & 53 & $31(58.49)$ & \\
\hline III, IV & 15 & $13(86.67)$ & \\
\hline Histological grade & & & 0.406 \\
\hline $\mathrm{G}_{1,2}$ & 33 & $23(69.70)$ & \\
\hline $\mathrm{G}_{3,4}$ & 35 & $21(60)$ & \\
\hline Renal vein invasion & & & 0.147 \\
\hline Yes & 11 & $5(45.45)$ & \\
\hline No & 57 & $39(68.42)$ & \\
\hline
\end{tabular}

NEDD9, neural precursor cell expressed, developmentally downregulated 9; TNM, tumor, node and metastasis.

Cell migration and invasion assay. The cell migration assay was performed using a 24-well transwell chamber with a pore size of $8 \mu \mathrm{m}$. In brief, $1 \times 10^{4}$ cells were seeded in the upper chambers in $200 \mu 1$ serum-free Dulbecco's modified Eagle's medium (DMEM; Corning Inc., Corning, NY, USA), and $750 \mu \mathrm{l}$ of 10\% FBS-DMEM (Invitrogen; Thermo Fisher Scientific, Inc.) was added into the lower wells. After $24 \mathrm{~h}$ at $37^{\circ} \mathrm{C}$, cells that had migrated to the bottom of the membrane were fixed and stained with $0.1 \%$ crystal violet in methanol in $15 \mathrm{~min}$ at room temperature. To quantify the cells, three independent fields per well were photographed under phase contrast microscopy. The number of cells per field were counted and averaged. For the cell invasion assay, the insert of the pore was coated with $50 \mu \mathrm{l}$ Matrigel (dilution at 1:2; BD Biosciences, Franklin Lakes, NJ, USA). All experiments were performed in triplicate.

Wound healing assay. A scratch wound-healing assay was performed to determine cell migration. Cells were seeded $\left(5 \times 10^{5}\right)$ into 6 -well plates the day before siRNA transfection. At $24 \mathrm{~h}$ after transfection, wounds were prepared using a $200 \mu \mathrm{l}$ pipette tip scratched through the wells. The cell migration speed was calculated by measuring the distance migrated in $24 \mathrm{~h}$. Images were obtained using a phase-contrast microscope at different time points ( 0 and $24 \mathrm{~h}$ ) after scratch. All experiments were performed in triplicate.
Statistical analysis. Data are presented as the mean \pm standard error of the mean. All statistical calculations were performed using SPSS 18 statistical software (SPSS, Inc., Chicago, IL, USA). The relative NEDD9 expression level in the matched tumor and normal renal tissues was calculated using a paired t-test. The Chi-square test was used to evaluate the association between NEDD9 expression profiles and clinicopathological factors. Survival analysis was performed using the Kaplan-Meier method and compared using the log-rank test. $\mathrm{P}<0.05$ was considered to indicate a statistically significant difference.

\section{Results}

Expression of NEDD9 in clinical RCC samples. To investigate the abnormalities of NEDD9 expression in RCC, NEDD9 expression was analyzed in 68 RCC tissues and 6 normal tissues using immunohistochemistry (Fig. 1). It was identified that NEDD9 protein was expressed in all RCC tissues RCC tissues and NEDD9 protein was highly expressed in 44 out of the 68 (64.71\%) NEDD9-positive patients with RCC, whereas normal renal tissues were $83.33 \%$ (5 of 6 ) negative, with a small number of samples exhibiting very low NEDD9 expression in the cytoplasmic region. These observations suggested that NEDD9 expression may be associated with RCC. 
A
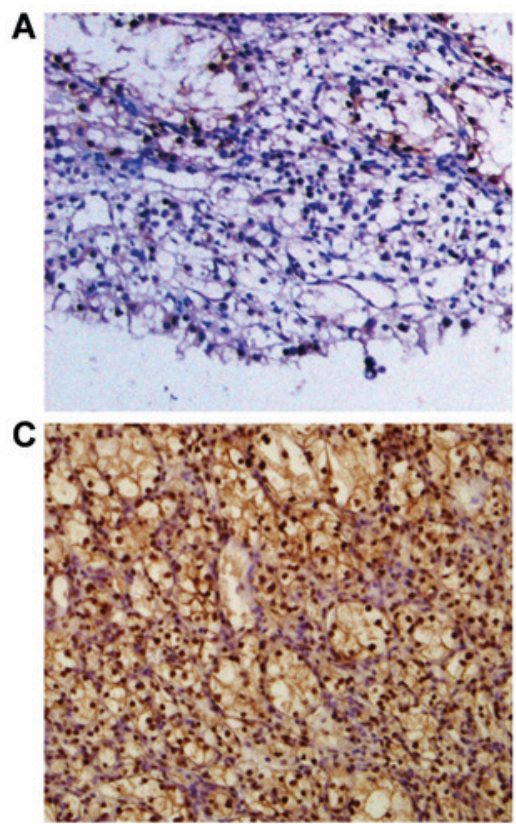

B

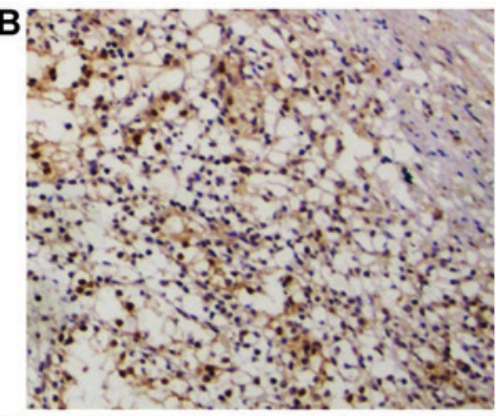

D

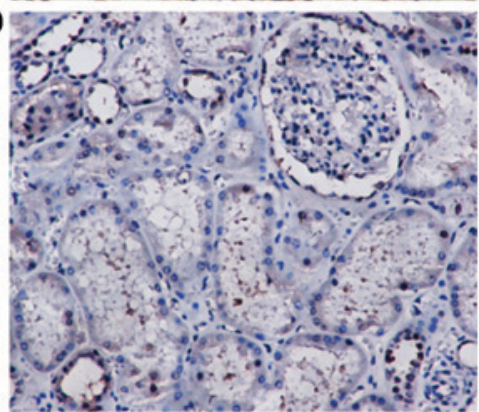

Figure 1. Immunohistochemical staining of NEDD9 protein in RCC samples. (A) Low NEDD9 expression in RCC tissues. (B) Moderate expression of NEDD9 in RCC tissues. (C) Strong expression of NEDD9 in RCC tissues. (D) Very low NEDD9 expression in normal renal tissue. RCC, renal cell carcinoma; NEDD9, neural precursor cell expressed, developmentally downregulated 9.

Association between NEDD9 expression levels and patient survival. The association between aberrant NEDD9 expression and clinicopathological factors was investigated. It was identified that the NEDD9 staining level was significantly associated with pathological tumor stage $(\mathrm{P}=0.011$; Table I) and advanced clinical TNM stage $(\mathrm{P}=0.045)$. No significant associations were observed between NEDD9 expression and patient sex, age or histological type (Table I). The log-rank test revealed that the survival time of patients with RCC overexpressing NEDD9 (37.5 \pm 6.49 months) was significantly shorter compared with patients with normal NEDD9 expression (57.67 \pm 7.24 months; $\mathrm{P}=0.0068$; Fig. 2).

Increased NEDD9 expression in RCC tissues. NEDD9 protein expression level was examined using western blotting in 20 pairs of frozen clinical ccRCC samples and matched normal renal tissues. NEDD9 expression was significantly higher in ccRCC tissues compared with matched normal renal tissues ( $\mathrm{P}<0.001$; Fig. 3A and B). Consistent with the NEDD9 protein expression profile, in ccRCC tissues, NEDD9 mRNA level was also significantly elevated, as detected by RT-qPCR analysis $(\mathrm{P}<0.001$; Fig. $3 \mathrm{C})$. The results indicated that NEDD9 is overexpressed in RCC specimens.

NEDD9 knockdown suppresses cell migration and invasion. First, it was demonstrated that NEDD9 siRNA could reduce NEDD9 mRNA and protein expression in different RCC cell lines (Fig. 4A and B). Next, transwell assays were performed to investigate whether migration and invasion of RCC cells would be attenuated by reduction of NEDD9 expression after transfection with NEDD9 siRNA. The results indicated that NEDD9 siRNA significantly reduced the migratory and invasive capability of 786-O and Caki1 RCC cells $(\mathrm{P}<0.0001$; Fig. 4C-F). In addition, a wound healing assay indicated that the migratory capacity of NEDD9 siRNA-treated cells was

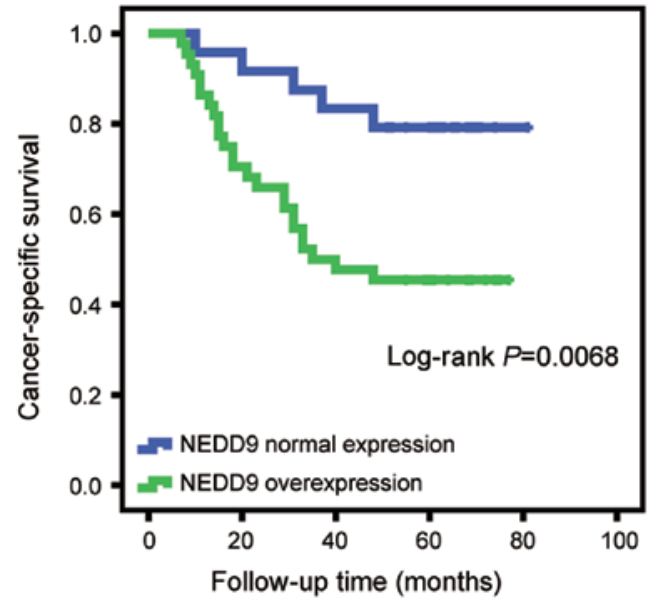

Figure 2. Kaplan-Meier analysis of cancer-specific survival according to NEDD9 expression in patients with renal cell carcinoma $(n=68)$. Patients with moderate to strong NEDD9 expression had a shorter survival time compared with patients with normal NEDD9 expression (24 patients exhibited normal expression and 44 patients exhibited overexpression in the 68 patient samples; $\mathrm{P}=0.0068$ ). NEDD9, neural precursor cell expressed, developmentally downregulated 9 .

significantly decreased at $24 \mathrm{~h}$ after scratch (ratios of wound closure: Scramble vs. NEDD9 siRNA, 786-O: $0.633 \pm 0.043$ vs. $0.200 \pm 0.032, \mathrm{P}<0.001$; Caki1: $0.850 \pm 0.022$ vs. $0.24 \pm 0.013$, $\mathrm{P}<0.001$; Fig. $4 \mathrm{G}$ and $\mathrm{H}$ ).

\section{Discussion}

RCC is the most common carcinoma of the adult kidney and the incidence of RCC has gradually increased in recent decades (1). Therefore, understanding the pathological mechanisms of RCC and identifying treatment targets is crucial. Previous studies have implicated NEDD9 as a central component of 

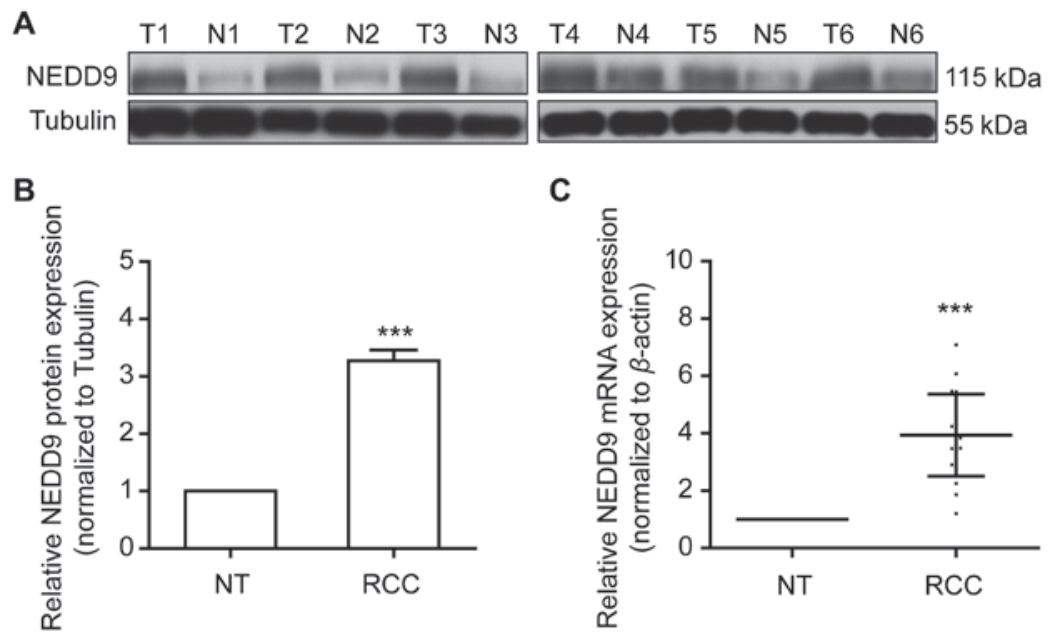

Figure 3. NEDD9 expression profiles in 20 pairs of ccRCC tissue and matched normal renal tissue. (A) Western blot analyses from 6 representative pairs of matched ccRCC and normal renal tissues. (B) Relative NEDD9 protein levels, as determined by western blot analyses. (C) Relative NEDD9 mRNA levels, as determined by reverse transcription-quantitative polymerase chain reaction. ${ }^{* * * *} \mathrm{P}<0.001 \mathrm{vs}$. NT. NEDD9, neural precursor cell expressed, developmentally downregulated 9; NT, normal tissue; RCC, renal cell carcinoma; ccRCC, clear cell RCC.
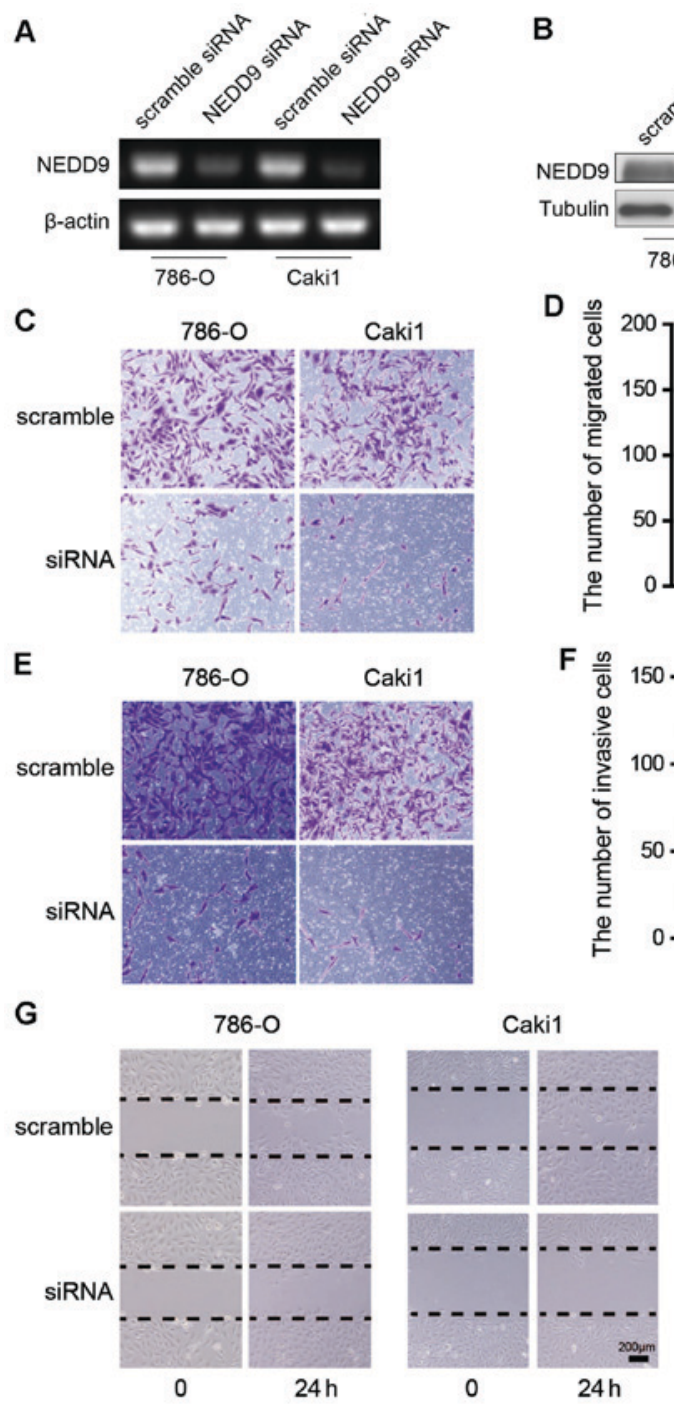

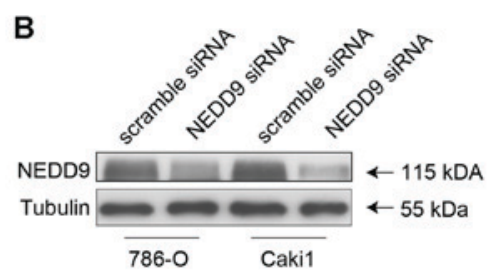

D
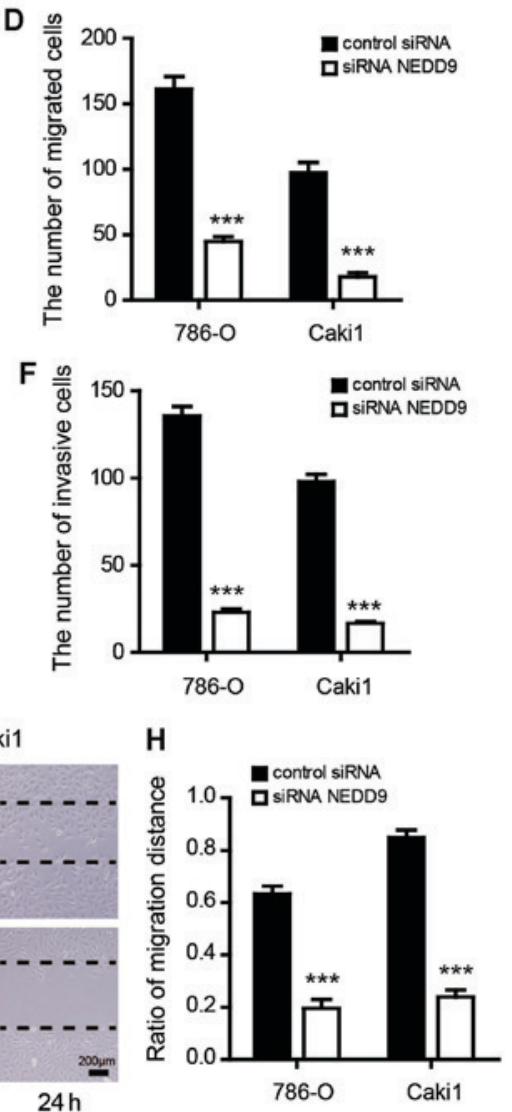

Figure 4. Effects of NEDD9 knockdown on cell migration and invasion. (A) Effects on NEDD9 mRNA expression after siRNA transfection for 48 h, as detected by reverse transcription semi-quantitative-polymerase chain reaction. (B) Effects on NEDD9 protein expression after siRNA transfection for $72 \mathrm{~h}$, as detected by western blot analysis. (C and D) Migration capacity of RCC cells was examined by transwell assay. (E and F) Invasion capacity of RCC cells was examined by Matrigel invasion assay. ( $\mathrm{G}$ and $\mathrm{H}$ ) Migration capacity of RCC cells was examined by wound healing assay. Data are presented as the mean \pm standard error of the mean $(n=3) .{ }^{* * *} \mathrm{P}<0.001$ vs. control siRNA. NEDD9, neural precursor cell expressed, developmentally downregulated 9; siRNA, small interfering RNA; RCC, renal cell carcinoma. 
integrin-dependent signaling cascades, which were identified to be activate the focal adhesion and Src kinases. NEDD9 thereby regulates activation of Src kinases and exhibits diverse functions, including apoptosis and cell cycle regulation, migration, adhesion, invasion and chemotaxis (16-18). Several studies have revealed aberrant expression of NEDD9 in various types of tumor, including colorectal cancer, gastric carcinoma, lung carcinoma and pancreatic carcinoma $(12,19,20)$. To the best of our knowledge, there are few studies focused on the role of NEDD9 in RCC, and the correlation of NEDD9 expression with the clinicopathological factors of RCC have not been determined.

The current study demonstrated that NEDD9 overexpression widely occurs in kidney cancer. The subcellular localization of endogenous NEDD9 in RCC tissues was evaluated by immunohistochemical staining. This indicated an intense staining of NEDD9 in $64.71 \%$ of RCC tissues. Statistical analysis of the clinicopathological features of patients with RCC in our study revealed that there was a significant association between NEDD9 overexpression and certain clinicopathological factors, such as primary tumor stage and tumor, node and metastasis stage. Furthermore, a high level of NEDD9 expression was significantly associated with the aggressive characteristics of RCC, such as pathological tumor stage and TNM stage. These observations are consistent with Shi et al (21), who reported that high NEDD9 expression exhibited a significant association with poor prognosis for gastric cancer patients. In addition, in the present study, threeto four-fold higher levels of expression of NEDD9 protein and mRNA were observed in tumor tissues compared with matched normal renal tissues in 20 paired RCC samples. These findings indicated that the upregulation of NEDD9 protein is involved in the progression and metastasis of RCC. To the best of our knowledge, this demonstrates the clinical and biological significance of NEDD9 in RCC for the first time.

Tumor metastasis caused by tumor cell invasion or metastasis is critical for cancer patient survival and it may reduce patient survival (22). The migration ability of tumor cells is believed to be the rate-limiting step in tumor metastasis; the migration of the tumor cell from the primary site to the surrounding tissue through the basement membrane is an important invasion function $(23,24)$. Recently, Feng et al (25) reported that NEDD9 depletion reduced the Matrigel invasion of gastric SGC-7901 and GES-1 cells. In the present study, a significant reduction in cell migration and invasion was observed in RCC cell lines. These results may explain the current findings that NEDD9 overexpression was the major defining characteristic of RCC tumors and was associated with numerous clinicopathological factors.

In conclusion, the present study has demonstrated that NEDD9 is upregulated in RCC, and high NEDD9 expression is associated with poor survival of patients with RCC. Inhibition of NEDD9 expression leads to attenuated migration and invasion ability. Therefore, NEDD9 may be a novel target for prevention and treatment of RCC.

\section{Acknowledgements}

The authors are grateful to the Central Research Laboratory, the Second Hospital of Shandong University (Jinan, China) for experimental techniques and generous support. This project was supported by the Seed Foundation of the Second Hospital of Shandong University (grant no. Y2015010039).

\section{References}

1. Siegel R, Naishadham D and Jemal A: Cancer statistics, 2013. CA Cancer J Clin 63: 11-30, 2013

2. Baldewijns MM, van Vlodrop IJ, Schouten LJ, Soetekouw PM, de Bruïne AP and van Engeland M: Genetics and epigenetics of renal cell cancer. Biochim Biophys Acta 1785: 133-155, 2008.

3. Drucker BJ: Renal cell carcinoma: Current status and future prospects. Cancer Treat Rev 31: 536-545, 2005.

4. Huang Y, Dai Y, Yang J, Chen T, Yin Y, Tang M, Hu C and Zhang L: Microarray analysis of microRNA expression in renal clear cell carcinoma. Eur J Surg Oncol 35: 1119-1123, 2009.

5. Shagisultanova E, Gaponova AV, Gabbasov R, Nicolas E and Golemis EA: Preclinical and clinical studies of the NEDD9 scaffold protein in cancer and other diseases. Gene 567: 1-11, 2015.

6. Kim M, Gans JD, Nogueira C, Wang A, Paik JH, Feng B, Brennan C, Hahn WC, Cordon-Cardo C, Wagner SN, et al: Comparative oncogenomics identifies NEDD9 as a melanoma metastasis gene. Cell 125: 1269-1281, 2006.

7. Natarajan M, Stewart JE, Golemis EA, Pugacheva EN, Alexandropoulos K, Cox BD, Wang W, Grammer JR and Gladson CL: HEF1 is a necessary and specific downstream effector of FAK that promotes the migration of glioblastoma cells. Oncogene 25: 1721-1732, 2006.

8. Tornillo G, Defilippi P and Cabodi S: Cas proteins: Dodgy scaffolding in breast cancer. Breast Cancer Res 16: 443, 2014.

9. Loskutov YV, Kozyulina PY, Kozyreva VK, Ice RJ, Jones BC, Roston TJ, Smolkin MB, Ivanov AV, Wysolmerski RB and Pugacheva EN: NEDD9/Arf6-dependent endocytic trafficking of matrix metalloproteinase 14: A novel mechanism for blocking mesenchymal cell invasion and metastasis of breast cancer. Oncogene 34: 3662-3675, 2015.

10. Kondo S, Iwata S, Yamada T, Inoue $\mathrm{Y}$, Ichihara H, Kichikawa $\mathrm{Y}$, Katayose T, Souta-Kuribara A, Yamazaki H, Hosono O, et al: Impact of the integrin signaling adaptor protein NEDD9 on prognosis and metastatic behavior of human lung cancer. Clin Cancer Res 18: 6326-6338, 2012.

11. Wang J, Yang WJ, Sun C, Luan Y, Cheng GH, Li KL and Kong F: siRNA suppression of NEDD9 inhibits proliferation and enhances apoptosis in renal cell carcinoma. Oncol Res 22: 219-224, 2014

12. Han T, Yi XP, Liu B, Ke MJ and Li YX: MicroRNA-145 suppresses cell proliferation, invasion and migration in pancreatic cancer cells by targeting NEDD9. Mol Med Rep 11: 4115-4120, 2015.

13. Izumchenko E, Singh MK, Plotnikova OV, Tikhmyanova N, Little JL, Serebriiskii IG, Seo S, Kurokawa M, Egleston BL, Klein-Szanto A, et al: NEDD9 promotes oncogenic signaling in mammary tumor development. Cancer Res 69: 7198-7206, 2009.

14. Eble J, Sauter G, Epstein J and Sesterhenn IE: World health organization classification of tumors pathology and genetics of the urinary systemandmale genital organs. LARC Press: Lyon, pp12-14, 2004.

15. Livak KJ and Schmittgen TD: Analysis of relative gene expression data using real-timequantitative PCR and the 2(-Delta Delta C(T)) method. Methods 25: 402-408, 2001.

16. Tikhmyanova N, Tulin AV, Roegiers F and Golemis EA: Dcas supports cell polarization and cell-cell adhesion complexes in development. PLoS One 5: e12369, 2010.

17. Nikonova AS, Gaponova AV, Kudinov AE and Golemis EA: CAS proteins in health and disease: An update. IUBMB Life 66: 387-395, 2014.

18. O'Neill GM, Seo S, Serebriiskii IG, Lessin SR and Golemis EA: A new central scaffold for metastasis: Parsing HEF1/Cas-L/NEDD9. Cancer Res 67: 8975-8979, 2007.

19. Xue YZ, Sheng YY, Liu ZL, Wei ZQ, Cao HY, Wu YM, Lu YF, Yu LH, Li JP and Li ZS: Expression of NEDD9 in pancreatic ductal adenocarcinoma and its clinical significance. Tumour Biol 34: 895-899, 2013.

20. Li P, Zhou H, Zhu X, Ma G, Liu C, Lin B and Mao W: High expression of NEDD9 predicts adverse outcomes of colorectal cancer patients. Int J Clin Exp Pathol 7: 2565-2570, 2014. 
21. Shi R, Wang L, Wang T, Xu J, Wang F and Xu M: NEDD9 overexpression correlates with the progression and prognosis in gastric carcinoma. Med Oncol 31: 852, 2014.

22. Wan L, Pantel K and Kang Y: Tumor metastasis: Moving new biological insights into the clinic. Nat Med 19: 1450-1464, 2013.

23. Zeng G, Gao L and Yu RK: Reduced cell migration, tumor growth and experimental metastasis of rat F-11 cells whose expression of GD3-synthase is suppressed. Int J Cancer 88: 53-57, 2000.
24. Shin KD, Lee MY, Shin DS, Lee S, Son KH, Koh S, Paik YK Kwon BM and Han DC: Blocking tumor cell migration and invasion with biphenyl isoxazole derivative KRIBB3, a synthetic molecule that inhibits Hsp27 phosphorylation. J Biol Chem 280: 41439-41448, 2005.

25. Feng J, Zhao J, Xie H, Yin Y, Luo G, Zhang J, Feng Y and Li Z: Involvement of NEDD9 in the invasion and migration of gastric cancer. Tumour Biol 36: 3621-3628, 2015. 